\title{
Computational Design Approach to Re-Establish the Urban Fabric of Mongla: A Perspective from Grasshopper
}

\author{
Sumaiya Binte Azad \\ Department of Architecture, Bangladesh University of Engineering and Technology (BUET), Dhaka, Bangladesh \\ email: sumjui51@gmail.com
}

\section{ARTICLE INFO}

\section{Article History:}

Received: 08th September 2021

Revised: 21st November 2021

Accepted: 23rd November 2021

Published: 23rd December 2021

\section{Keywords:}

Mongla urban design

Computational urban design

Grasshopper-Physarealm modelling

Urban fabric

\begin{abstract}
A B S T RAC T
The Padma Multipurpose Bridge Project is the genesis of some subsequent projects in Bangladesh among which developing Mongla Port is one of the priority values. Since Mongla is an integral part of southern Bangladesh, the government has taken initiatives to integrate the port uses for neighboring countries. An agreement was signed (Intra Bangladesh, Butan, India, and Nepal (BBIN) Trade) for offering multi-modal transit access to India and Port access to Nepal, Bhutan and Eastern India. The objective of this study is to establish a computational way to analyze the existing fabric and restore a potential optimized fabric. The methodology of this study includes developing a computational approach, collecting data from secondary sources, analyzing the data set and adjusting it to the identified existing urban fabric. In this paper, a new tool is introduced named 'Physarealm', based on the algorithm of Grasshopper and Rhinoceros.
\end{abstract}

\section{INTRODUCTION}

Since the existing condition of communication infrastructure of Mongla port from the capital Dhaka as well as the borders is not up to the mark; the government of Bangladesh has set a new embellishment for the transportation system in southern parts of the country. According to the pre-feasibility report Mongla Economics Zone Bangladesh, the city economy was developed based on the port-oriented trade which was the main Central Business District (CBD) not only of this particular zone but the whole southern part of the country. Mongla could be referred to as a 'secondary city' in a developing country like Bangladesh which plays an explicitly influential position in regional economies. Besides, this city not only moulds the livelihood character of its urban residents but the working people of the industrial units within and around the district.

This research will demonstrate a new way towards a 2dimensional systematic proposition instead of an analogous thinking approach and analyse the existing as well as a potential urban fabric of the Mongla port area. In recent times, the parametric design process is such a structured approach that evaluates a design via algorithm and ensures minimal assessment time while providing data accessible throughout the development phase (Motta, 1999). Designing has been a crucial aspect of our life; for years, perception of design sometimes has failed and some approaches have devastated both financial and physical resources. In addition, intuition sometimes could be misleading and strenuous whereas computer-aided programs could lend support in complex and comprehensive experimental analysis (Mawla et al., 2018). Computer-aided designs can also perform in multitudinous directions at a time like- density, population, environment, energy, integration, material, distance, speed, time, demand etc.

On the account of Bangladesh endeavouring to establish a Digital Bangladesh programme, 'Smart city Campaign' has been launched recently. This project aims to emphasize improved urban environment and decentralization of facilities. These include the improvement of urban infrastructure such as vehicular and pedestrian connectivity, sewerage system, waste management, drinking water, energy-efficient techniques, communitylevel infrastructure. According to the authority, urban areas are the engines of economic growth and so the authority aims to develop economic corridors to integrate industry, infrastructure, urban services, institutional and regulatory framework (Acharjee, 2020).

Computational designs can lead to a future that minimizes rational errors. This study helps to relocate the existing bus and water terminal under the concept of Transit Oriented Development (TOD), considering the land use and other Infrastructure facilities in terms of land use pattern, existing urban fabric, transportation, environmental consideration, and last but not least, the physical and visual 
accessibility to and from the stations.

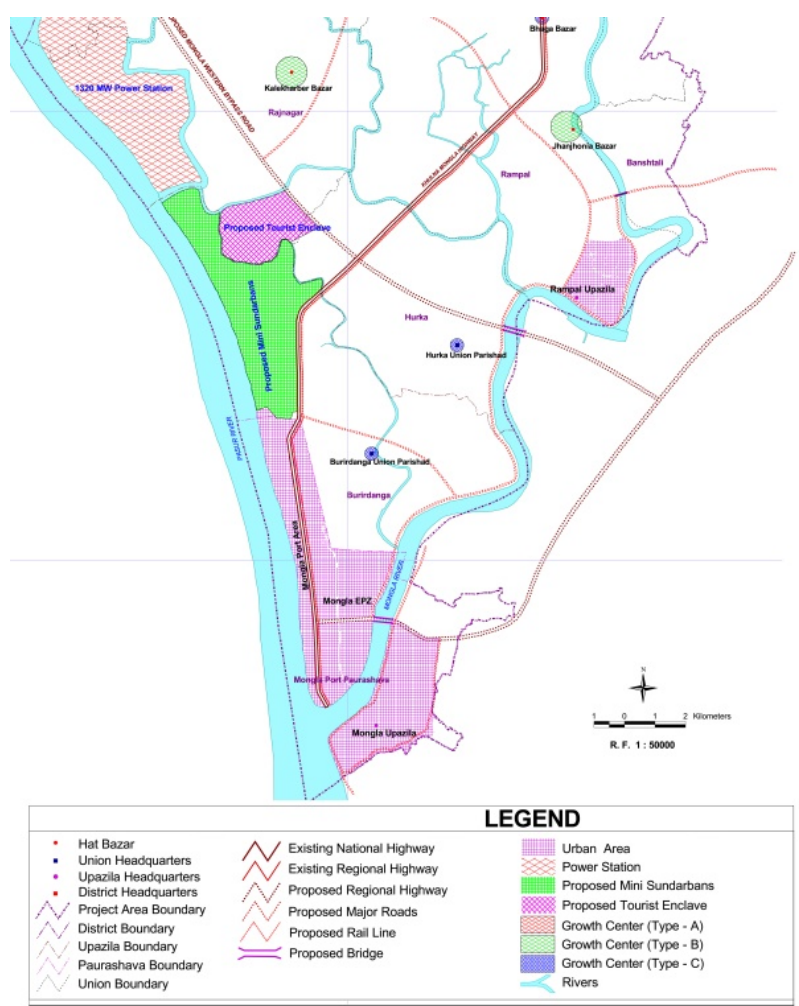

Figure 1: Land use pattern of Mongla Port Paurashva

\section{COMPUTATIONAL DESIGN APPROACH}

By 2050, there is a probability that $70 \%$ of the world's population will start living in megacities which indicates a mass of 10 million citizens. This data depicts that, there should be a whole new target-oriented, interdisciplinary programmed and well-structured approach in urban planning and design in cities (Renner, 2018). Subsequently, planners from across the world are tending to adopt computational methods. Accordingly, the presented framework depicts that, the use of digital tools and programming methods can be used for extensive research experiments while the outcomes can be computed in no time. A methodical algorithmic approach undoubtedly increases planning efficiency and variety at the same time.

\section{EXISTING URBAN FABRIC}
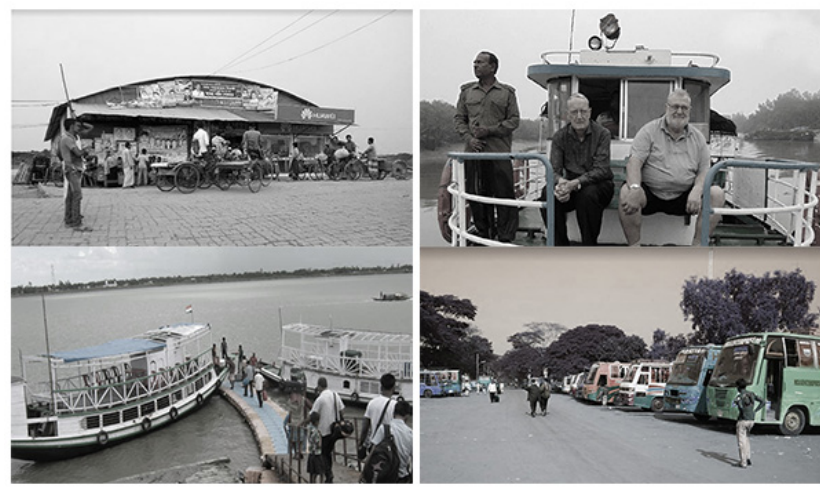

Figure 2: a, b, c, d from left to right; existing bus and water terminal
In the existing condition, an expiring bus stand and moribund water terminal works as the multi-modal transportation hub for years featured in Figure 2(a, b, c, d) as well as public transport is almost non-existent in Burirdanga UP \& Mongla Port Paurashva. The EPZ alone offers 611 employment opportunities per hectare (total EPZ area is around 205 acres/83 hectares approx.). The existing fabric is pretty much fragmented and the spatial segments are isolated in terms of connectivity and infrastructures. The existing urban fabric can be divided into three grids; they are:

\section{A. The connectivity grid}

Connections and accessibilities of the area, which include vehicular roads, pedestrian networks, cycling tracks, etc.

\section{B. The activity grid}

Consists of public zones, residential zones, facility zones, service areas.

\section{The green infrastructure grid}

Comprises open public spaces, green networks, retaining water bodies, urban sprawl, permeable pavements, green roofs, trees and tree boxes, and rainwater harvesting systems.

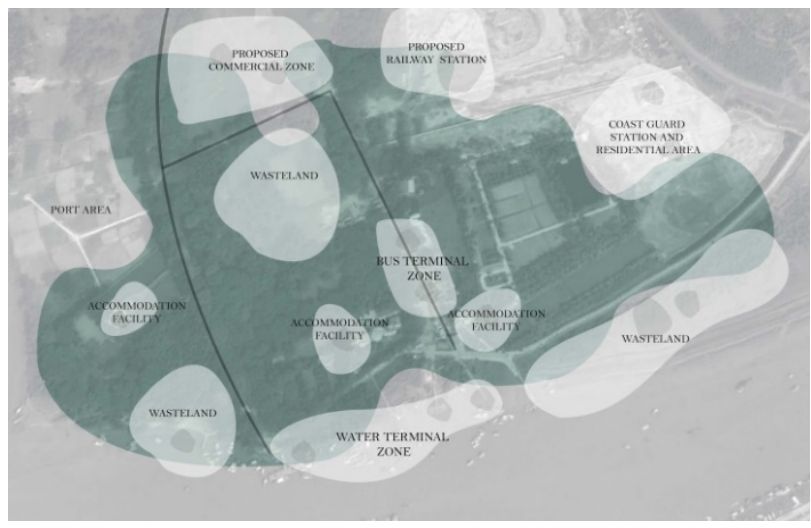

Figure 3: existing urban fabric

\section{LITERATURE REVIEW}

As discussed earlier, research has been conducted worldwide on computational urban planning and its spatial attributes. However, a research gap remains on Mongla, the city is one of the flourishing cities of Bangladesh which is not only the gateway to the Sundarbans but-constituents second largest seaport, export processing zone, power plant, fishing, and many other private industrial zones. According to Feisal and Kuhl (2021) Mongla has the potential for positive transformation of secondary cities. Parametric modelling authorizes engendering extensive urban design permutations that resemble sustainable design development targets.

So far, there are several computational methods and tools available for indirect urban fabric analysis, such as space syntax (Conroy-Dalton \& Bafna, 2003), Isovists analysis (Batty, 2001), density-based quantitative analysis (Hausleitner, 2010), and Rhinoceros based plugin Grasshopper (Schneider, Koltsova, \& Schmitt, 2011). 
Rapid urbanization sometimes endangers many historical precincts with indigenous characters disappearing, present scenario of China indicates an urban fabric crisis (Ruan \& $\mathrm{Gu}$ 2004). Modern cities undergo both energy problems (Polsky, 2014) and fragmentation caused by isolated building pattern, communication networks, and negative spaces (Trancik, 1986), converting the buildings into random pieces. Therefore, urban fabric assessment is considered as the cardinal aspect for developing a smart city (Li. 2016). It is also argued that the visual exposure of urban space which includes -buildings, public space, road network, differentiates cities from others (Proshansky, Fabian and Kaminoff, 1983). In short, proper urban fabric planning and design is the paramount objective for a smart city.

The emergent trait of swarms and self-organizing attributes have turned them into popular appliances among architects of the computational field, as well as their strategic approach against complexity and the diversified possibility they comprise (Pantic \& Hahm, 2015). A team of Japanese and Hungarian researchers has shown that Physarealm can find the shortest route between two food sources when set in a maze with two oatmeal flakes (Nakagaki et al. 2000). In a survey from 2010, Physarealm created a network similar to the existing routes of the train system of the Tokyo area (Tero et al. 2010). Since then, researchers have been using Physarealm modelling for the spatial formation study and to apply architecture-planning sectors.

\section{OBJECTIVES}

The goal of the study is to develop an intelligent transportation infrastructure of the area through computational progress for the betterment of local people, to provide the commuters a convenient as well as congenial walking courses, to create a buffer yet easy access among all terminals, reducing walking distances in between the terminals and eliminating passenger - vehicle conflict points, designating particular areas for services and finally, increasing the number of existing facilities.

\section{COMPUTATIONAL METHODOLOGY}

\section{A. Addressing the algorithm}

Software - Rhinoceros 3D is popular commercial Computer-Aided-Design software developed by Robert McNeel \& Associates for designers, architects, planners which is based on fundamental programmed geometric parameters. A Rhinoceros-based plugin 'Grasshopper' is used to create a prototype of a circulation pattern. 'Physarealm' is an agent-based stigmergy algorithm modelling, programmed on Physarum Polycephalum and similar to the ant colony algorithm. P.Polycephalum is a slime mold that inhabits shady, cool, moist areas such as decaying leaves and logs.

The presented model reproduces the biological behaviour of Physarum; which are formation, growth and minimized transport networks. We can delineate the basic pattern from these simulation outcomes by simplifying them. Hereby, we can find different shapes of routes chosen by slime by connecting several nodes. Several trails were extracted from the generated slime movement patterns time to time.

\section{B. Computation process}

The site is located near the Mongla port. If the TOD radius is taken as $1 \mathrm{~km}$ according to the standard of the Dhaka Mass Rapid Transit Development Project (TOD) Report, the possible outcome is shown in Fig.3a. However, the existing bus and water terminal lies right next to the upcoming railway station.

The simulation was run several times based on different parameters like - population, density, speed, and flexibility. The result was fascinating which could be portrayed as a basic physical pattern.

Step1. Assessing the survey data and integrating with Grasshopper and Physarealm.

Step2. Place Physarealm and connect the primary data set with it- like environment (surfaces, geometry, and boundary), emitter points, foods, population etc.

Step3. Set up the additional settings like- Chemo field, death-birth rate, angles, etc. and run the simulation for 3-4 hours until it achieves stability.
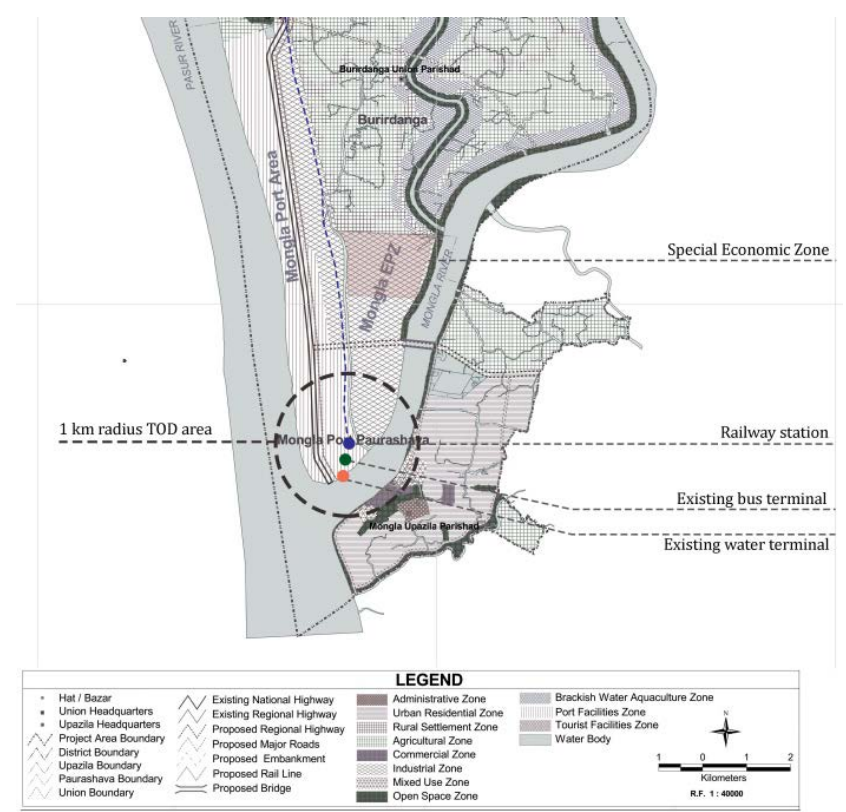

Figure 4: Land use pattern of TOD area and surroundings

\section{Tools}

Rhinoceros is primarily an organic surface modeling system that utilizes the NURBS mathematical model. Rhinoceros incorporates specific fields such as rendering and animation, architecture and planning, engineering, prototyping, and others. The integrated plugin tool'grasshopper' allows parametric measures for design proposal which runs different kinds of simulations and experiments. Recently, in the contemporary architecture field, Grasshopper is one of the most premier programming engines for planners, exceeding in networking, urban planning, digital fabrication, generative art, simulation depending on numeric, geometric, visual variables. It has become user-friendly not only due to its high flexibility but efficiency and swift exploratory experiences as well. 


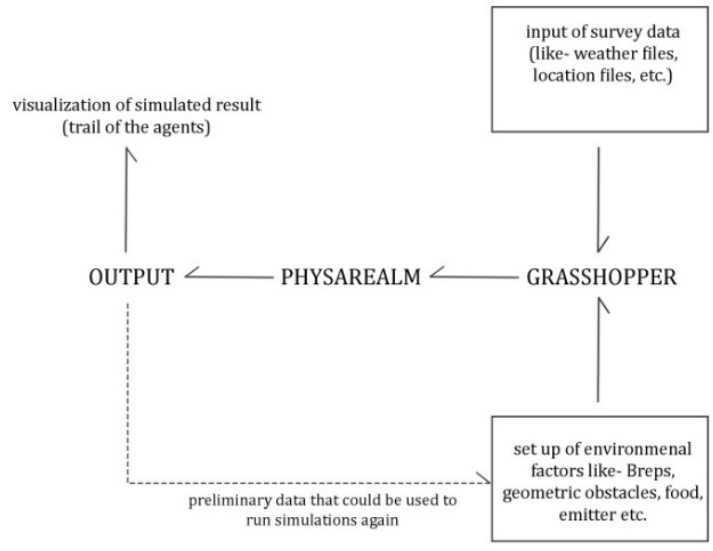

Figure 5: workflow with Physarealm.
Environment: Contains the eps file of the particular environment and location, comprises 3D modeling atmosphere. The agents can move at any orientation in the 3D lattice-based model. The eps file is integrated within the modeling with a Brep container which operates in 3D orientation.

Obstacle: Users can assign physical obstacles as Breps within the grid as well as a barrier aligned with the site line. A customized high escape possibility may manipulate the regulations and allow the agents to enter obstacles. In this study, an old mosque plaza (local landmark), a chunk of old trees and a canal were maintained as obstacles in the last four scenarios. Apart from that, for the first two simulations, the surface was maintained as barren land.

Surface: A defined 2D or 3D surface area to start with, performs perfectly for either file- Brep or geometric shapes.

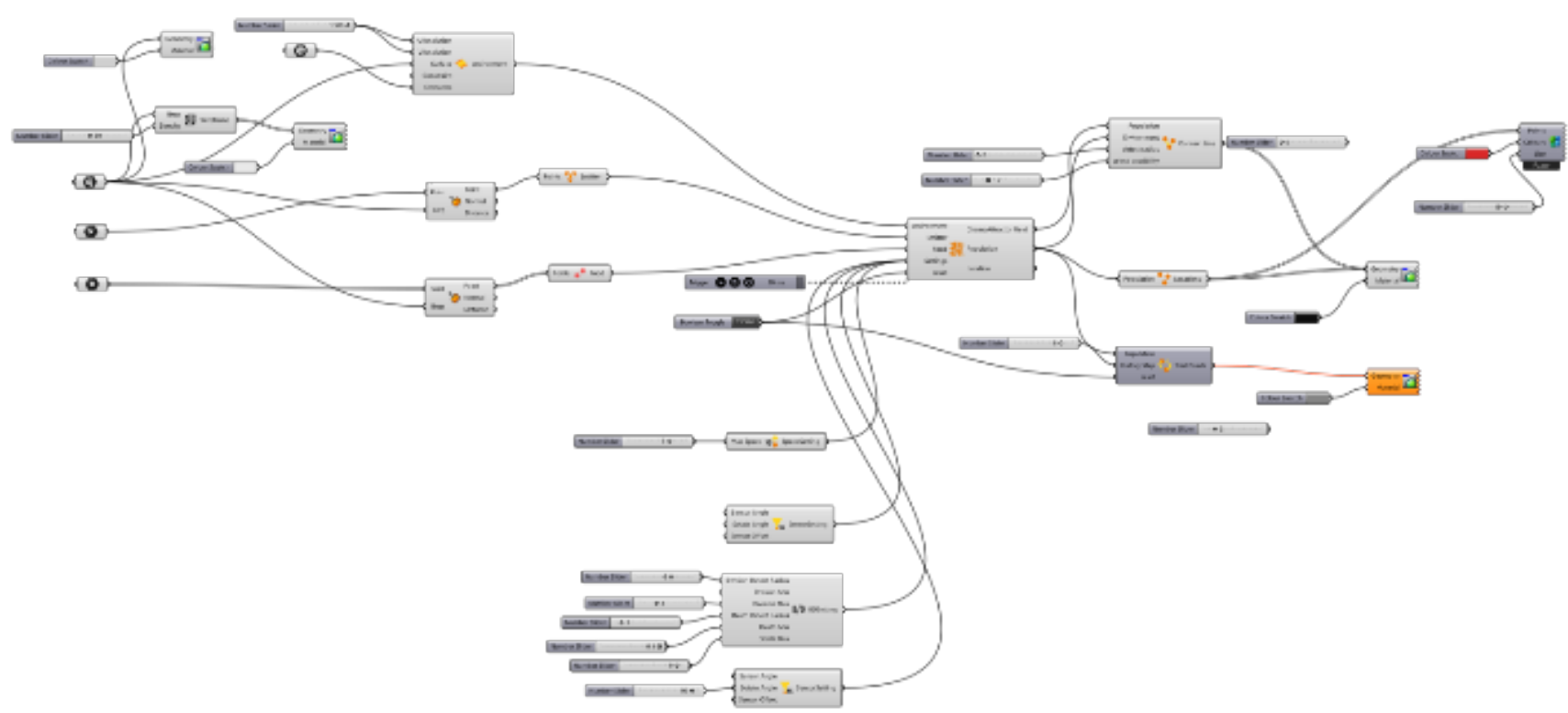

Figure 6: Environmental parameters from Physarealm

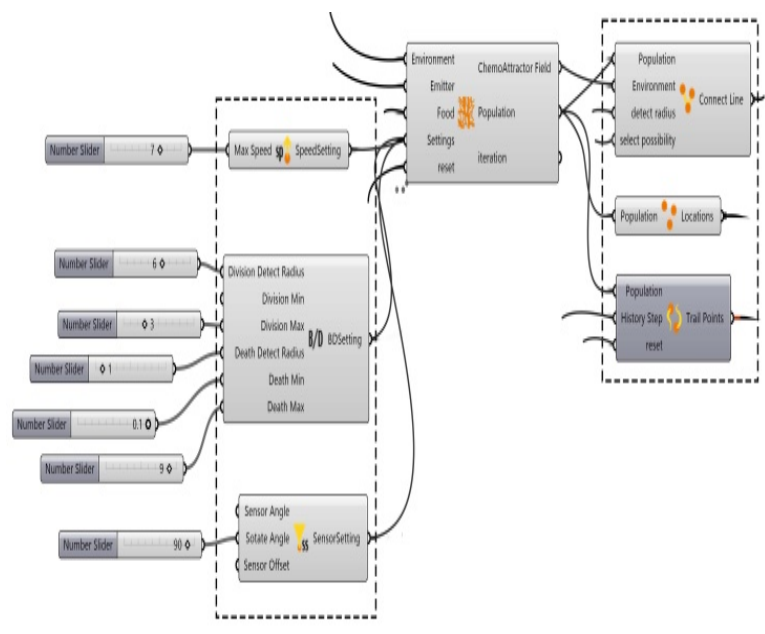

Figure 7: parameters from Physarealm

Emitter: A set of point containers, generate agents near the specified locations and provide them random orientations.
The bus terminal, railway station, water terminal etc. could serve as the emitters since people are dispersed from these hubs.

Food: Serves as the destination of the agents. These sets of points constantly emit chemo-attractive trails to attract the agents. The foods could represent the destination points e.g. public plazas, accommodation facilities, commercial zones, market spaces, residential areas etc. 'Food' provokes the agents to find a way among them in terms of minimized walking distance and time.

The additional settings are: Speed max. 7 10, sensor angle $0,30,60,90$, detect radius $5 \sim 8$, division max 3 , death radius $1 \sim 3$, death min0.1 0.3, death max $6 \sim 9$, sotate angle 90 .

The output variables are:

Chemo attractor field: Attracts the agents depending on the value given. Every agent has multiple sensors to detect the level of chemo-attractive trail concentrations in front of it. This could represent the techniques like signboards, 
digital direction boards, etc.

Population: Number of agents to experiment with, in this case between 100- 300 .

In addition, added values of birth-death rates (5-10), sensor angles (multiple of 30) in the settings, happen to manipulate the outcome. The live formulation and growth of the programmed mold can be supervised in grasshopper which leaves some trails according to the movement of the agents. The 'trail point' is the rudimentary pattern developed by the agents which depict the minimal distances among the destinations of the algorithm.

Possibility range $0.1 \sim 0.3$, detect radius $0 \sim 2$, history step 5 9, Boolean Toggle and reset button attached to reset option to operate independently.

\section{Analysis and interpretation}

In the figure shown in $5 \mathrm{a}$, we can observe the raw trails constructed at several time-lapse which were manipulated by the measures described before.
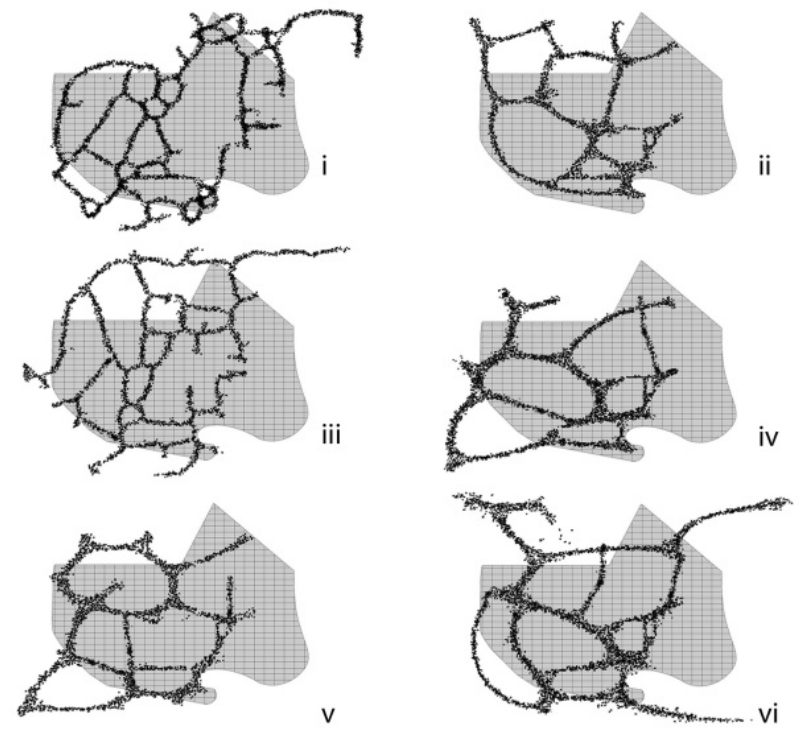

Figure 8 : sample simulation patterns from Physarealm

To the best knowledge, after gathering a good number of samples (at 4-5 hours per run), a simplified pattern was generated. Some sample patterns shown in Fig 5a, represent common specimens which are shown in Fig. 5b. At first, the simulation trails were simplified and the food nodes were identified. The trail curves were traced with digital media and at last, the simplified lines were inferred.

The simplified reference wireframe paves the way to propose some major changes in connectivity. The simplified traced trail sets were again stacked on each other and a sketch was delineated. In Fig.6, we can see the simplified connection grid according to the computational design process. The proposed grid results in several fragmented zoning which could serve as urban buffer spaces. The foods are represented by dots and the dotted lines symbolize the minimal distance trail patterns from the simulation.
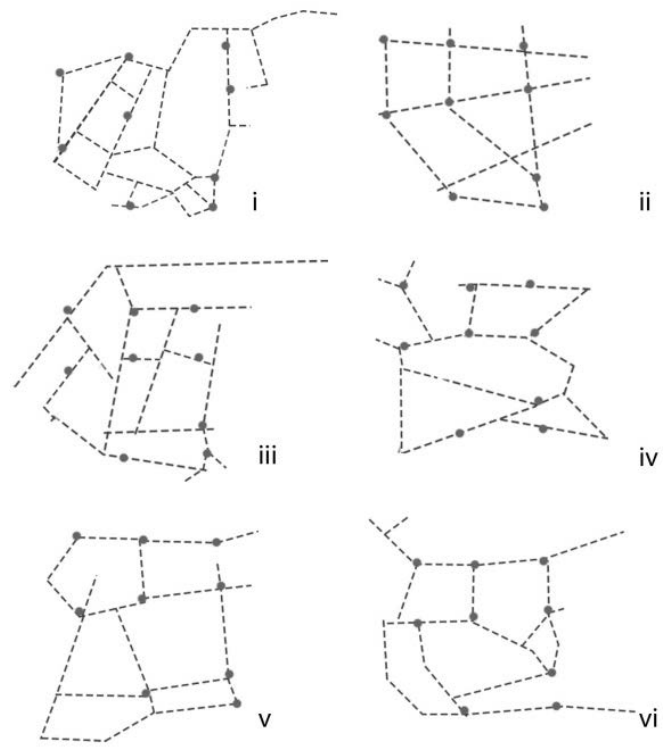

Figure 9: simplified patterns from simulations

\section{OVERVIEW AND VISUALIZATION}

We can delineate a basic trail from the generated simplified patterns which are shown in Fig. 6. The fundamental sketch depicts that, the grid should be something like this.

- railway station

- bus terminal

- water terminal

- port area

- riverfront areas

The final output of the calculation modifies the three major grids:

- $\quad$ The connectivity grid - vehicular and pedestrian connections and accessibility.

- The activity grid - public spaces and facilities, accommodations.

- The green infrastructure grid - green network which serves as natural urban buffer spaces.

a. Port facility zone - proposed in KMDP development management plan 2011-2031, situated in between the river and railway station.

b. Railway station plaza - connected with the N7 highway via proposed connecting road (ii \& iii/Figure 6).

c \& f. Economic district - Proposed EPZ and special economic zone.

d. Urban buffer zone - consists of existing forest office, accommodation facility and coast guard station at present. The proposed urban zone should be enriched with natural resources, green landscape and waterscape.

e. Bus terminal zone - situated in the existing bus stand area, the capacity and efficiency should be maximized.

g. Public recreation zone and accommodation zone located in the area of existing urban open space at present. Riverfront development is suggested like - boat club, 
cycling and pedestrian tracks, sitting arrangements etc.

h. Water terminal zone - the terminal should be upgraded with modern amenities and facilities since this is one of the main access points of the world's largest mangrove forest, the Sundarbans. To promote tourism, there is no other option but to improve the connectivity grid.

i. Coast guard station and forest office - is suggested to be relocated to this zone since zone 3 and 5 are potential sites for urban breathing with huge natural resources.

\section{A. Connectivity grid}

The access points to the site are:

- $\quad$ N7 highway extension

- $\quad$ Proposed approach road to EZ

- $\quad$ Proposed connecting road to the bypass road.

- $\quad$ Proposed one-way connection towards the bypass (through the hub to maintain a loop)

- $\quad$ Proposed one-way road to complete a loop.

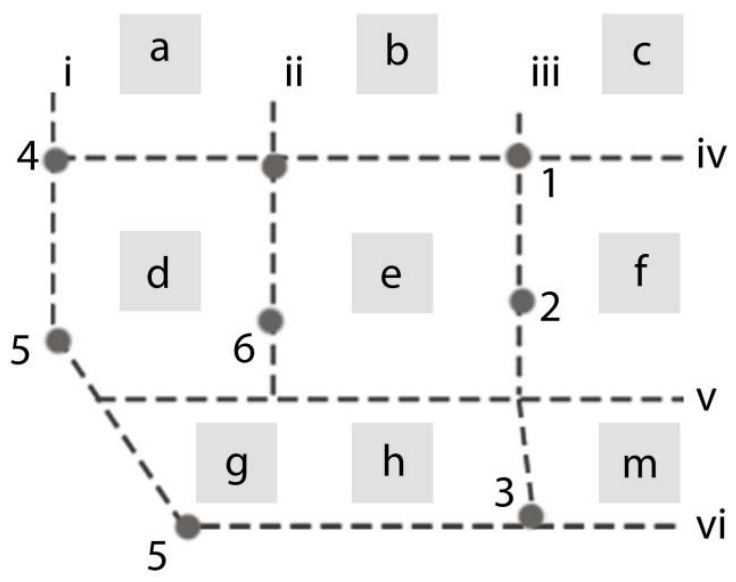

Figure 10: Proposed non-vehicular access.

\section{B. Activity grid}

Public plazas can be placed tactfully to define different zones and to avoid any chaos which may serve as urban buffer spaces place to place. In this case, the public recreation zone is consistent with the existing condition which works perfectly, optimized by the public itself.

The riverbank development area offers visitors to enjoy the sublime beauty of the confluence, which is situated at the dead-end of the N7 highway, right beside the port premises. The complementary composition of the riverbank, the sunset on the horizon along with incoming ships towards the port, offers a majestic atmosphere. This zone may be developed as public recreation zone with modern facilities and amenities. The portside plaza offers a vast natural landscape for public amusement and facilities like- exhibition, public gathering, amphitheatre, cycling track, outdoor sports ground, early development, youth entertainment, family and friends, pet corner, gym area etc. It is situated not so far from the terminals so; the visitors or tourists can always make a little escape from the hectic long run. The plaza is well distinguished from the water terminal and the bus terminal by the accommodation facility zone, shown in Figure 7.

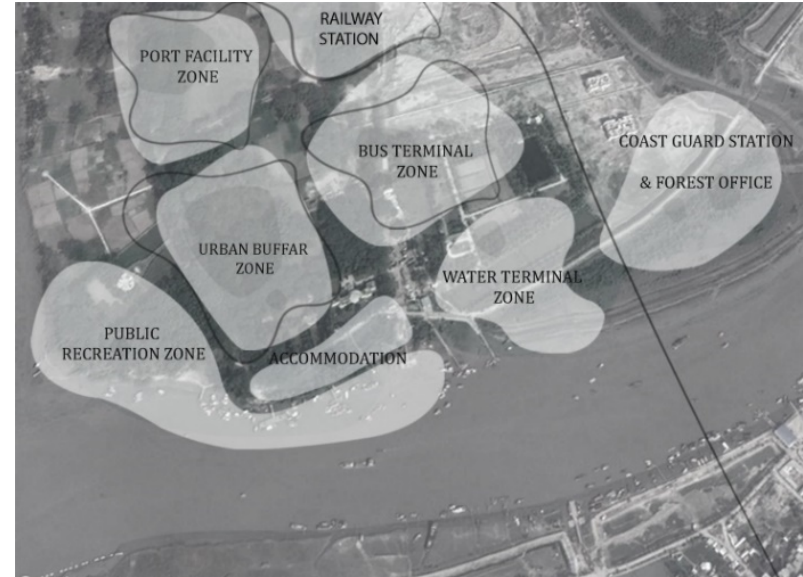

Figure 11: visualization of proposed urban fabric

The existing accommodation facility may be enriched by developing the neighbourhood recreation zone. This facility area separates the central urban zone and the riverbank plaza.

\section{Green infrastructure grid}

Zone d - The buffer area should be used as an urban green space to check the chaos and sound between the hub and the rest of the zones. The quality may be enhanced by a natural preservation program along with basic infrastructural systems which include sitting arrangement, rainwater reservoir, stormwater swale, retention drains, pedestrian and cycling tracks etc. This new chunk may be stretched out through the medians and pedestrian networks and connect with other green chunks.

\section{CONCLUSIONS}

Once the prototype analytical file is set up, the evaluation and simulation could be easily manipulated for further innovation. From this study, we can negotiate that there are further possibilities in terms of zoning and connectivity in Mongla port area. A new way can be portrayed the extended connectivity grid and the activity grid as well from this computer-aided design study. PhysarealmGrasshopper has been used in urban connectivity and morphology, parametric landscape and digital fabrication at large. A park pathway is established based on Physarealm, among several sports facility premises congregated by an Olympic stadium (Yidong, 2017).

In short, the presented framework depicts that the use of digital tools and programming methods can be used for extensive research while the outcomes can be computed in no time. The computational approach undoubtedly increases the planning efficiency and variety at the same time. The work with the parametric plug-in Grasshopper offers comprehensive and user-friendly approaches in the generation of various designs.

Once the computational linguistics is achieved data interpretation and schematic plan can be ended in a very short period of time along with the digital fabrication of the whole design process. This suggested wireframe reveals a highly potential experimental program that could take months to reach up to this point. In this age of modernism and advanced technology, computational 
design process is the most methodical and productive perspective.

Future study will concentrate on the absolute 3Dimensional formation of morphological features hopefully due to the intricate survey study and extensive methodology.

\section{REFERENCES}

Acharjee Deepak, (2020), The Independent, February 5th, Four metropolitan cities to turn into 'smart cities' Rhinoceros 3d application.

Source: https://en.wikipedia.org/wiki/Rhinoceros_3D, Extracted on July 21, 2021.

Apps for Rhino and Grasshopper, Source: https://www.food4rhino.com/en/app/physarealm, Extracted on July 21, 2021.

Batty M., (2001) "Exploring isovist fields: Space and shape in architectural and urban morphology," Environ. Planning B, vol. 28, no. 1, pp. 123-150.

Conroy-Dalton R. \& Bafna S., (2003) “'The syntactical image of the city: A reciprocal definition of spatial elements and spatial syntaxes,"' in Proc. 4th Int. Space Syntax Symp., pp. 59.1-59.22.

Detailed Area Plan [Mongla] Port Paurashva DAP.

Executive summary draft: pre-feasibility report Mongla Economics Zone Bangladesh/pp 32-33

Fink T., Koenig R. (2019), Data - city information modelling and GIS - Volume 3 - eCAADe 37 / SIGraDi 23, pp 313

Hausleitner B., (2010) “Tracing scopes of action. Approaching the complexity of the urban block," M.S. thesis, EMU, Delft, The Netherlands.

Koenig R., Knecht K., Buš P., (2017) Koenig R. et al "Interactive Urban Synthesis- Computational Methods for Fast Prototyping of Urban Design Proposals".

Li X. et al. (2016): Assessment of Urban Fabric for Smart Cities.

Mawla A.,Schneider S., Bielik M., Koenig R. (2018), Integrated Data Analysis for Parametric Design Environment, mineR: a Grasshopper plugin based on R 36th eCAADe Conference - Computing for a better tomorrow pp. 320

Motta, E 1999, Reusable Components for Knowledge

Modelling: Case Studies in Parametric Design Problem Solving, IOS Press.

Nakagaki, T., Yamada, H. and Toth, A.: (2000), Intelligence: Maze-solving by an amoeboid organism, Nature, pp. 470470 .
Pantic, I. and Hahm, S.: 2015, Isomorphic Agency, Emerging Experience in Past, Presentand Future of Digital Architecture, Proceedings of the 20th International Conference of the Association for Computer-Aided Architectural Design Research in Asia CAADRIA, pp.178188

Polsky C. et al. (2014), “Assessing the homogenization of urban land management with an application to US residential lawn care," Proc. Nat. Acad. Sci. USA. vol. 111, no. 12, pp. 4432-4437,

Pre-Feasibility Report-Mongla Economic Zone, Bangladesh. (2015), pp 139-140.

Proshansky H. M., Fabian A. K., and Kaminoff R., (1983), 'Place-identity: Physical world socialization of the self,' J. Environ. Psychol., vol. 3, no. 1, pp. 57-83.

Rahman f. \& Kuhl L. (2021) "Putting Mongla on the Map: The Curious Case of a Coastal Secondary City's Transformation”. In United Nations Research Institute for Social Development. Source: https://www.unrisd.org/transformation-mongla, Extracted on July 20, 2021.

Renner, R (2018), Urban Being, Anatomy \& identity of the city, Salenstein.

Ruan Y., and Gu X., (2004) "An analysis about the practical patterns to conserve the historic districts in China," J. Tongji Univ. Soc. Sci., vol. 15, no. 5, pp. 1-6.

Schneider, C., Koltsova A., Schmitt G, ETH Zurich. (2011) "Components for Parametric Urban Design in Grasshopper. From Street Network to Building Geometry"/pp 68

Spring Simulation Multi-conference, SpringSim '11, Boston, MA, USA.

Status paper on Asian highway Bangladesh (2011), Roads Division, Ministry of Communications Bangladesh.

Tero, A., Kobayashi, R. and Nakagaki, T.: (2007), A mathematical model for adaptive transport network in path finding by true slime mold, Journal of theoretical biology, pp. 553-564

The Preparatory Study on the Dhaka Mass Rapid Transit Development Project (TOD), Final Report, pp-3_158

Trancik R., (1986), Finding Lost Space: Theories of Urban Design. New York, NY,

Volume 8: Proceedings of the 2011 Symposium on Simulation for Architecture and Urban Design (SimAUD).

Yidong M., Weiguo X., (2017), Proceedings of the 22nd International Conference of the Association for ComputerAided Architectural Design Research in Asia (CAADRIA) 2017, pp 499-509. 